\title{
Structural VAR, MARMA and Open Economy Models
}

by

Phoebus J. Dhrymes, Columbia University

Dimitrios D. Thomakos, Columbia University

November 1997

Discussion Paper Series No. 9798-07

$$
\begin{aligned}
& \text { de } 9798 \cdot 07 \\
& \text { pages } 31
\end{aligned}
$$




\title{
Structural VAR, MARMA and Open Economy Models
}

\author{
Phoebus J. Dhrymes and Dimitrios D. Thomakos* \\ Columbia University
}

November 1997

\section{Introduction}

The objective of this paper is to examine the recent literature on the standard open economy macro paradigm. Since there are many aspects to this literature, we concentrate on issues regarding the nature of restrictions imposed in order to gain identification, the general problem of identification in the context of the standard strctural VAR (SVAR) or structural MARMA (SMARMA) model ${ }^{1}$ employed for that purpose, the question of whether "forward" looking (rational) expectations (FLE) are more in accord with the empirical evidence than the standard "backward" looking (rational) expectational (BLE) schemes and, finally, whether the results one obtains are invariant to the choice of model specification as SVAR or SMARMA.

* We would like to thank Richard Clarida for useful discussions.

${ }^{1}$ The acronym SMARMA stands for structural multivariate autoregressive moving average (model). 


\section{Formulation of the Problem and Literature Review}

The general problem examined here has had a lengthy development in the literature, spurred by the generalized adoption of floating exchange rates, and the concern to determine the 'causes' of real exchange rate fluctuations. Mussa (1986) argues for sluggish price adjustments; Stockman (1987) argues for the presence of real shocks with large permanent components; Huizinga (1987) argues that real exchange rates after the float possess a unit root, which leads to greater variability. Campbell and Clarida (1987) argue that real interest differentials cannot account for much of the variation in real exchange rates, and that strong PPP fails to hold. Meese and Rogoff (1988) doubt the validity of the basic "sticky price" open macro model due to Dornbusch (1976). They note that if money is neutral in the long run then, at best, nominal shocks may affect real exchange rates only in the short run if at all. Instead they consider a stochastic version of the two country rational expectations open macro model due to Obstfeld (1985) and its antecedents. This model in its many subsequent variations is currently en vogue, and it is the model we shall employ in this paper. The model is enunciated with great clarity in Taylor (1993). The modification we shall make to Taylor's representation is that we shall take wages as exogenous, thus avoiding the data difficulties that would be occasioned due to the characterization of current wages as the filtered outcome of prior wage contracts.

Thus, following Taylor (1993) as modified above, the model in its long run equilibrium conditions consists ${ }^{2}$ of the usual IS (income-savings) equation

$$
I_{t}=-d r_{t}+f\left(e_{t}+p_{t}^{*}-p_{t}\right)+g I_{t}^{*},
$$

where $I, r, e, p, m, i$ stand for the "home" country (real) GDP, real interest, exchange rate, GDP deflator, money stock, and nominal interest

\footnotetext{
${ }^{2}$ In this literature all variables except the nominal interest rate appear as natural logarithms.
} 
rate, respectively, and the starred entities stand for the corresponding variables in the "other" country. Variables with a caret indicate expectational variables. The price equation

$$
p_{t}=\theta w_{t}+(1-\theta)\left(e_{t}+p_{t}^{*}\right)
$$

represents an equilibrium assertion that domestic prices are a "CobbDouglas" function of the (own) wage rate and foreign (other) prices.

The usual demand for money equation may be inverted (renormalized) so that it is written as an interest equation

$$
i_{t}=\frac{a}{b} y_{t}-\frac{1}{b}\left(m_{t}-p_{t}\right)
$$

The purchasing power parity condition may be rewritten as an exchange rate equation

$$
e_{t}=\hat{e}_{t+1}-\left(i_{t}-i_{t}^{*}\right)
$$

and finally, as a matter of definition, one writes the real interest rate as

$$
r_{t}=i_{i}-\hat{\pi}_{t},
$$

where $\hat{\pi}_{t}$ is the expected rate of inflation; the latter is further defined by

$$
\hat{\pi}_{t}=\hat{p}_{t+1}-p_{t}
$$

In such models the money stock $\left(m_{t}\right)$ is taken to be exogenous; as usual, expectational variables, say $\hat{p}_{t+1}$ and $\hat{e}_{t+1}$, indicate the conditional mean of the variables in question as represented in the solution of the model, conditioned on the $\sigma$-algebra generated by the error process over $(-\infty, t]$. This is the so called forward looking rational expectations (FLE) view; the alternative view, perhaps the backward looking (BLE) view, substitutes for $\hat{p}_{t+1}$ and $\hat{e}_{t+1}, \hat{p}_{t}$ and $\hat{e}_{t}$, respectively, so that they are conditioned on the $\sigma$-algebra generated by the error process over $(-\infty, t-1]$.

Empirical implementation typically adds short run dynamics and operates with the reduced form, which is thus a standard VAR with a 
certain number of lags. However, in this fashion the economics of the model are lost, and one typically seeks to recapture the "structure" imposed above using various aspects of the (estimated) reduced form error process.

\section{Identification Issues}

In order to elucidate the identification issues involved we require a more convenient notation. Identification issues are the same whether one employs a structural VAR (SVAR) or a structural MARMA (SMARMA) model. We illustrate the problem in the case of SVAR. To this end write the "structural" model above together with its short-run dynamics as

$$
y_{t} . \Pi(L)=\epsilon_{t .}, \quad t=1,2, \ldots, T
$$

where $\Pi(L)=\sum_{j=0}^{n} \Pi_{j} L^{j}$, where $n \geq 1, L$ is the usual lag operator, $\Pi_{j}$ is a $q \times q$ matrix, the roots of $|\Pi(z)|=0$ lie outside the unit circle and $\Pi_{0}$ is a nonsingular matrix. In the standard VAR representation of Eq. (7) above, it is assumed that $\epsilon=\left\{\epsilon_{t}: t \in \mathcal{N}\right\}$ is i.i.d. with mean zero and covariance matrix either $I_{q}$, or $D$, where $D$ is a diagonal matrix. In the former case $\Pi_{0}$ is left unrestricted, except for restrictions imposed by the economics of the problem, while in the latter case a normalization convention is imposed so that $\Pi_{0}=I_{q}-\Pi_{0}^{*}$, such that the diagonal elements of $\Pi_{0}^{*}$ are all zero. In the two cases the covariance matrix of the reduced form errors

$$
u_{t .}=\epsilon_{t} \cdot \Pi_{0}^{-1}
$$

is given, respectively, by

$$
\operatorname{Cov}\left(u_{t}^{\prime}\right)=\Pi_{0}^{\prime-1} \Pi_{0}^{-1}, \text { and } \operatorname{Cov}\left(u_{t}^{\prime}\right)=\Pi_{0}^{\prime-1} D \Pi_{0}^{-1},
$$

where in the second case $\Pi_{0}$ has unities along its main diagonal, and $D$ is the (diagonal) covariance matrix of the structural errors.

When the covariance matrix of the structural errors is taken to be the identity matrix, $I_{q}$, identification, Sims (1980), is obtained by the 
decomposition of the reduced form covariance matrix, i.e. if $\Omega$ is the reduced form covariance matrix, we may decompose it as $\Omega=P^{\prime} P$ and make the identification $P=\Pi_{0}^{-1}$. Since the decomposition of a positive definite matrix is arbitrary to within an orthogonal matrix it was suggested that the (unique) triangular decomposition be obtained. Notice that this implies that the system is triangular, i.e. the variables may be reordered if necessary so that the first (endogenous) variable is independent of the others; the second depends only on the first; the third depends at most on the first and second and so on. ${ }^{3}$ A second identification approach, suggested by Blanchard and Quah (1989) and elucidated in Lestrapes (1992) and in Clarida and Gali (1995), imposes "long run" restrictions using the apparatus of the old dynamic multiplier analysis based on distributed lags, see for example Dhrymes (1971), (1981). The argument proceeds as follows: Put, in the standard case,

$$
\Pi(L)=\Pi^{*}(L) \Pi_{0}, \quad y_{t}=\epsilon_{t} \cdot[\Pi(L)]^{-1}=\epsilon_{t} \cdot \Pi_{0}^{-1}\left[\Pi^{*}(L)\right]^{-1} .
$$

If the polynomial operator $\Pi(L)$ has roots outside the unit circle, its inverse is well defined. Imagine now two regimes; the first in which the i.i.d. sequence is $\epsilon=\left\{\epsilon_{t}: t \in \mathcal{N}\right\}$ and another in which the i.i.d. sequence, say $\epsilon^{*}$, is identical to the $\epsilon$ sequence, except that $\epsilon_{1}^{*}=\epsilon_{1}+\eta$, where $\eta$ is a zero mean finite variance random vector independent of the $\epsilon$ sequence. The difference, $d_{t}$, in the two resulting sequences $y_{t}$. and $y_{t}^{*}$. is given by

$$
y_{t .}^{*}-y_{t}=d_{t .}=\eta B_{t-1}, \quad[\Pi(L)]^{-1}=\sum_{i=0}^{\infty} B_{i} L^{i} .
$$

The "long run" condition of Blanchard and Quah is that $[\Pi(1)]^{-1}$ be upper triangular. Since

$$
\Pi(L) \Pi_{0}^{-1}=\Pi^{*}(L), \quad\left[\Pi^{*}(1)\right]^{-1}=\Pi_{0}[\Pi(1)]^{-1} .
$$

\footnotetext{
${ }^{3}$ For the uniqueness of the triangular decomposition of a positive definite matrix see Dhrymes (1970), (1984).
} 
Consequently, using Eq. (12) we find

$$
\begin{aligned}
{\left[\Pi^{*}(1)\right]^{\prime}-1 \Omega\left[\Pi^{*}(1)\right]^{-1} } & =[\Pi(1)]^{\prime-1} \Pi_{0}^{\prime}\left(\Pi_{0}^{\prime-1} \Pi_{0}^{-1}\right) \Pi_{0}[\Pi(1)]^{-1} \\
& =[\Pi(1)]^{\prime-1}[\Pi(1)]^{-1}
\end{aligned}
$$

The point of Eq. (13) is that its leftmost component may be estimated by least squares methods through the estimation of a standard VAR, thus obtaining the estimators

$$
\hat{\Pi}^{*}(1)=\sum_{j=1}^{n} \hat{\Pi}_{j}^{*}, \text { and } \hat{\Omega}=\frac{1}{T} \hat{U}^{\prime} \hat{U}, \quad \hat{U}=Y-\sum_{j=1}^{n} Y_{-j} \hat{\Pi}_{j}^{*}
$$

where $\hat{\Pi}_{j}^{*}$ are the least squares estimators of the standard VAR (reduced form) coefficients obtained from the representation

$$
y_{t}=\sum_{j=1}^{n} y_{t-j} \Pi_{j}^{*}+\epsilon_{t} \cdot \Pi_{0}^{-1} .
$$

If we obtain the (unique) triangular decomposition, see Dhrymes (1970), (1984), pp. 15-16, pp. 68-69, respectively,

$$
\left[\hat{\Pi}^{*}(1)\right]^{\prime-1} \hat{\Omega}\left[\hat{\Pi}^{*}(1)\right]^{-1}=S^{\prime} S,
$$

and use Eq. (12) we find

$$
S=[\hat{\Pi}(1)]^{-1}=\left[\hat{\Pi}_{0}\right]^{-1}\left[\hat{\Pi}^{*}(1)\right]^{-1},
$$

or, alternatively,

$$
\hat{\Pi}_{0}=\left[\hat{\Pi}^{*}(1)\right]^{-1} S^{-1}
$$

Remark 1. In both cases identification is obtained by just identifying conditions. As shown in the early literature of simultaneous equations, see for example Dhrymes (1994), just identification is simply a reparametrization of the reduced form, and in no way sheds any light on the structure of the system. This fact was also pointed out in the open economy macro literature by Lestrapes (1992). Notice further that 
just identifying restrictions are nontestable. Thus, two just identifying sets of conditions, which have diametrically opposed economic implications may well have the same empirical justification, viz. the estimates of the reduced form parameters in the context of which they are applied. As such they do not add anything further to our understanding of the economic phenomenon in question over the above what was conveyed by the reduced form, and they are both equally defensible or equally subject to severe criticism.

Notice, further, that the Sims identification restrictions, in the language of simultaneous equations, represents the SVAR as a just identified simply recursive system, see Dhrymes (1970) pp.303-311, which "explains" why such parameters may be estimated, in this case uniquely, by least squares and indirect least squares.

\section{Empirical Implementation}

\subsection{The Model and its Estimation}

The model we shall estimate is a modification of that given in Eqs. (1) through (6) and will be represented as a somewhat more complex version of the model in Eq. (7), with the following variable identification: the number of variables is $q=5$. The ordering of variables: $y_{t 1}=I_{t}$ is real GDP; $y_{t 2}=p_{t}$ is GDP deflator; $y_{t 3}=i_{t}$ is the 90 day Treasury bill rate; $y_{t 4}=e_{t}$ is the exchange rate defined defined as US $\$ / F C$, where $\mathrm{FC}$ indicates foreign currency; finally, $y_{t 5}=m_{t}$ is the stock of money defined, for all countries dealt with in this paper, as M1. Plain (unstarred) variables refer to the "home" country, here the US; starred variables refer to the "other" country, here alternatively Germany, Japan, and the UK.

Because the model as exhibited in Eqs. (1) through (6) incorporates already a number of prior restrictions and normalizations, we choose to ultimately represent the model as in Eq. (7) and impose such restrictions by means of Lagrange multipliers. This will enable us routinely to test 
the validity of such prior restrictions, to the extent that we have overidentification. For this see Dhrymes (1994a). If we substitute for $r_{t}$ and $\hat{\pi}_{t}$ in the first equation, we see that the model contains two expectational variables, $\hat{e}_{t+1}, \hat{p}_{t+1}$, which are to be interpreted as the conditional expectation of the corresponding variables given the $\sigma$-algebra generated by the error process over $(-\infty, t]$. This implies that these expectational variables are functions of the exogenous variables of the model at "time" $t$. In addition, the nature of Eq. (1) suggests a certain linear restriction on its parameters. Similarly Eqs. (2), (3) and (4) suggest that certain variables are absent, i.e. that their corresponding coefficients are zero. Finally we wish to test the assumption regarding the exogeneity of money stock. To this end we introduce the fifth equation of the model as $m_{t}=b m_{t-1}$. This states that $m_{t}$ does not depend on the other current endogenous variables of the model; consequently, we may test the hypothesis of exogeneity by testing the corresponding Lagrange multipliers. Thus, the "structural" version of this model may be written as

$$
y_{t} \cdot \Pi_{0}=x_{t} \cdot C
$$

where $x_{t}$. is the vector of exogenous (here generally the other country variables) and own M1. If we add also short run dynamics, the models we shall actually estimate are of the form

$$
\begin{aligned}
y_{t} \cdot \Pi_{0}+y_{t-1} \cdot \Pi_{1}+x_{t} \cdot C & =\epsilon_{t} \cdot+\epsilon_{t-1} \cdot A_{1}, \text { SMARMA } \\
y_{t} \cdot \Pi_{0}+y_{t-1} \cdot \Pi_{1}+y_{t-2} \cdot \Pi_{1}+x_{t} \cdot C & =\epsilon_{t} . \text { SVAR }
\end{aligned}
$$

where $\epsilon=\left\{\epsilon_{t}\right.$. : $\left.t \in \mathcal{N}\right\}$ is a sequence of i.i.d. random vectors with mean zero and covariance matrix $I_{q}$. The method of estimation is given in Dhrymes (1997) and the restrictions we shall impose are given below, where we write the elements of $\Pi_{0}$ as 


$$
\Pi_{0}=\left[\begin{array}{ccccc}
\pi_{11} & \pi_{12} & \pi_{13} & \pi_{14} & \pi_{15} \\
\pi_{21} & \pi_{22} & \pi_{23} & \pi_{24} & \pi_{25} \\
\vdots & \vdots & \vdots & \vdots & \vdots \\
\vdots & \vdots & \vdots & \vdots & \vdots \\
\pi_{51} & \pi_{52} & \pi_{53} & \pi_{54} & \pi_{55}
\end{array}\right]
$$

The restrictions imposed on $\Pi_{0}$ are given in Table 1 below.

\section{Table 1}

Parametric Restrictions on $\Pi_{0}$ of Eq. (20).

\begin{tabular}{|r|r|l|l|}
\hline Eq. & Restriction & & Comment \\
\hline \hline 1 & $\pi_{21}-\pi_{31}+\pi_{41}$ & $=0$ & \\
\hline 2 & $\pi_{12}=\pi_{32}=\pi_{52}$ & $=0$ & Exclusions \\
\hline 3 & $\pi_{43}$ & $=0$ & Exclusion \\
\hline 3 & $\pi_{23}+\pi_{53}$ & $=0$ & No Money Illusion \\
\hline 4 & $\pi_{14}=\pi_{24}$ & $=0$ & Exclusions \\
\hline 4 & $\pi_{34}$ & $=1$ & Parity Condition \\
\hline 5 & $\pi_{15}=\pi_{25}=\pi_{35}=\pi_{45}$ & $=0$ & Exogeneity of Money \\
\hline \hline
\end{tabular}

In the last row of the table above we represent the exclusion restrictions for the case of the BLE rational expectations scheme. In the FLE expectations scheme, since $m_{t}$ is an exogenous variable and is, thus, part of the linear combination that represents $\hat{p}_{t+1}$ and $\hat{e}_{t+1}$, we have fewer restrictions. Hence the number of overidentifying restrictions we may test must be less than four. Consequently, the full exogeneity of money cannot be tested. But we may test for permutations of three zero restrictions in the last equation. 


\subsection{Data}

The data employed in this study have been obtained from the International Financial Statistics (CD-ROM) monthly data file and are as follows: GDP in real terms, always expressed in billions of (1990) US dollars; ${ }^{4}$ GDP deflator in index form; exchange rates as indicated earlier; interest rate is expressed in percentage terms, and for the US, UK, Germany and Japan is the 90 -day treasury bill rate or equivalent. Generally, the exogenous variables in the right member of Eq. (20) are, in addition to M1, the "other" (foreign) variables, which from the point of view of the US are taken to be exogenous. Our data series are as follows: for Germany and Japan we have monthly observations over the period 1979:1 to 1996:10; for the US and the UK monthly observations over the period 1973:1 to 1996:10.

\subsection{Estimation Issues}

A great deal of the open economy macro literature in recent times has dwelled on issues of whether the series above are $I(1)$ or even $I(2)$.

Since our interest in this paper does not lie in that direction we have taken the somewhat neutral position of operating entirely in first differences.

The estimation of parameters for such models is treated extensively in Dhrymes (1997). Basically for SMARMA ${ }^{5}$ one operates with the (reduced) form

$$
y_{t}+y_{t-1} \cdot \Pi_{1} \Pi_{0}^{-1}+x_{t} \cdot \Pi_{0}^{-1}-\epsilon_{t-1} \cdot \Pi_{0}^{-1}\left(\Pi_{0} A_{1} \Pi_{0}^{-1}\right)=\epsilon_{t} \cdot \Pi_{0}^{-1},
$$

\footnotetext{
${ }^{4}$ Actually this series is available only in quarterly terms. We have interpolated between quarters to obtain monthly series since all other variables are available in monthly frequencies.

${ }^{\mathbf{5}}$ It is customary in time series literature to refer to ARMA models with exogenous variables as ARMAX; thus the model actually implement may be more appropriately termed SMARMAX.
} 
or, in the obvious notation

$$
y_{t .}+y_{t-1} \cdot \Pi_{1}^{*}+x_{t} \cdot \Pi_{0}^{*}+u_{t-1} \cdot A_{1}^{*}=u_{t .} .
$$

Notice that the characteristic roots of the AR part, i.e. those of $\mid I+$ $\Pi_{1}^{*} z \mid=0$ are precisely those of $\left|\Pi_{0}+\Pi_{1} z\right|=0$ and that the characteristic roots of the MA part, i.e. those of $\left|I-A_{1}^{*} z\right|=0$ are precisely those of $\left|I-A_{1} z\right|=0$. Thus, the stability properties of the system are not disturbed. The estimation procedure obtains estimators for $\Pi_{1}^{*}$ and $A_{1}^{*}$ by nonlinear methods and concetrates the $(\log )$ likelihood function as

$$
L\left(\Pi_{0} ; Y, X\right)=c_{0}+\frac{T}{2} \ln \left|\Pi_{0} \Pi_{0}^{\prime}\right|-\frac{T}{2} \operatorname{tr} \Pi_{0}^{\prime} \hat{\Omega} \Pi_{0}
$$

which is to be maximized with respect to $\Pi_{0}$ subject to the constraints given in Table 1 , i.e.

$$
R \pi=r, \quad \pi=\operatorname{vec}\left(\Pi_{0}\right)
$$

where the elements of $R$ and $r$ are given by the entries in the table above.

The situation is essentially the same for SVAR, except that the first stage of estimation is quite simple because of the linearity of the first order conditions. In this case we introduce two lags so as to equalize the number of parameters in the two cases.

Reduced form coeficients are almost never presented in the empirical open economy macro literature. We have, for our part, computed the correlation coefficients between predicted and actual values of the dependent variables. They are reported in the Appendix in Tables A6 and A7.

\section{Empirical Results}

We consider first the tests of the overidentifying restrictions. We observe, from Table 1, that in the FLE version, as we have formulated it, 
there are 13 restrictions. On the other hand the BLE version contains 14 restrictions. Identification of the feedback matrix $\left(\Pi_{0}\right)$ requires a minimum of 10 restrictions (just identification). Evidently, we cannot test the validity of all 13 or 14 restrictions. But we may, on the assertion that 10 restrictions are true test three or four such restrictions, based on their marginal asymptotic distribution.

The relevant Lagrange multiplier tests are given in Tables 2 and 3 below for the forward and backward looking expectations schemes, respectively.

\section{Table 2}

Tests of Overidentifying Restrictions

Forward Looking Expectations (SMARMA)

\begin{tabular}{|r|r|r|r|r|r|}
\hline \hline Eq. & Restriction & & Tests GER & Tests JPN & Tests UK \\
\hline \hline 1 & $\pi_{21}-\pi_{31}+\pi_{41}$ & $=0$ & $7 \mathrm{e}-5(\mathrm{~A})$ & $8 \mathrm{e}-5(\mathrm{~A})$ & $8 \mathrm{e}-6(\mathrm{~A})$ \\
\hline 2 & $\pi_{12}=\pi_{32}=\pi_{52}$ & $=0$ & $16.05^{* * *}(\mathrm{R})$ & $21.93^{* * *}(\mathrm{R})$ & $0.96(\mathrm{~A})$ \\
\hline 3 & $\pi_{43}$ & $=0$ & $1 \mathrm{e}-4(\mathrm{~A})$ & $8 \mathrm{e}-5(\mathrm{~A})$ & $6 \mathrm{e}-6(\mathrm{~A})$ \\
\hline 3 & $\pi_{23}+\pi_{53}$ & $=0$ & $2 \mathrm{e}-5(\mathrm{~A})$ & $2 \mathrm{e}-5(\mathrm{~A})$ & $5 \mathrm{e}-6(\mathrm{~A})$ \\
\hline 4 & $\pi_{14}=\pi_{24}$ & $=0$ & $0.12(\mathrm{~A})$ & $0.07(\mathrm{~A})$ & $0.008(\mathrm{~A})$ \\
\hline 4 & $\pi_{34}$ & $=1$ & $-0.002(\mathrm{~A})$ & $-0.002(\mathrm{~A})$ & $0.694^{* * *}(R)$ \\
\hline 5 & $\pi_{15}=\pi_{25}=\pi_{35}=\pi_{45}$ & $=0$ & $(\mathrm{~A})$ & $(\mathrm{A})$ & $(\mathrm{A})$ \\
\hline \hline
\end{tabular}

In the preceding, and all other tables, we employ the convention that a *, ${ }^{* *},{ }^{* * *}$ indicates significance at the $10 \%, 5 \%$ and $1 \%$ level, respectively.

In the last row of Table 2 the notation $(A)$ indicates that all permutations of any three of the enumerated restrictions are accepted.

The test results reported in the first row give confirmation of an essential aspect in this literature, viz. that it is the real interest rate 
and the real exchange rate that are major determinants of GDP. The result indicates that it is accepted in all cases.

The results in the second row indicate that the exclusion restrictions for the price equation are strongly rejected for the US vis-a-vis Germany and Japan, but not the UK. We chose not impose nor test the hypothesis that US prices are a homogeneous of degree one Cobb-Douglas function of US wages and foreign prices since this would be inappropriate in a bilateral context but would be an important hypothesis to be tested in the case of the US vis-a-vis either the big seven or the rest of the world.

The results in the third row indicate that the exclusion of the exchange rate from the interest equation is uniformly accepted.

The results in the fourth row confirm that the no money illusion hypothesis is appropriate, and it is unformly accepted.

The results in the fifth row indicate that the major restriction implied by the parity condition, i.e. that the domestic interest rate is uniquely related to the exchange rate, is accepted for Germany and Japan but is strongly rejected for the UK.

The results in the last row indicate that the exogeneity of money is uniformly accepted although we may not fully test this hypothesis, but only subsets of three of the four implied restrictions. Nonetheless the evidence is in favor of exogeneity.

\section{Table 3}

Tests of Overidentifying Restrictions Backward Looking Expectations (SMARMA) 


\begin{tabular}{|r|r|r|r|r|r|}
\hline \hline Eq. & Restriction & & Tests GER & Tests JPN & Tests UK \\
\hline \hline 1 & $\pi_{21}-\pi_{31}+\pi_{41}$ & $=0$ & $1 \mathrm{e}-4(\mathrm{~A})$ & $1 \mathrm{e}-4(\mathrm{~A})$ & $1 \mathrm{e}-4(\mathrm{~A})$ \\
\hline 2 & $\pi_{12}=\pi_{32}=\pi_{52}$ & $=0$ & $24.94^{* *}(\mathrm{R})$ & $21.89^{* * *}(\mathrm{R})$ & $33.02^{* * *}(\mathrm{R})$ \\
\hline 3 & $\pi_{43}$ & $=0$ & $-0.001(\mathrm{~A})$ & $9 \mathrm{e}-4(\mathrm{~A})$ & $1 \mathrm{e}-4(\mathrm{~A})$ \\
\hline 3 & $\pi_{23}+\pi_{53}$ & $=0$ & $3 \mathrm{e}-5(\mathrm{~A})$ & $6 \mathrm{e}-6(\mathrm{~A})$ & $8 \mathrm{e}-5(\mathrm{~A})$ \\
\hline 4 & $\pi_{14}=\pi_{24}$ & $=0$ & $0.017(\mathrm{~A})$ & $0.018(\mathrm{~A})$ & $0.055(\mathrm{~A})$ \\
\hline 4 & $\pi_{34}$ & $=1$ & $-0.011(\mathrm{~A})$ & $-0.008(\mathrm{~A})$ & $-0.002(\mathrm{~A})$ \\
\hline 5 & $\pi_{15}=\pi_{25}=\pi_{35}=\pi_{45}$ & $=0$ & $2.68(\mathrm{~A})$ & $2.22(\mathrm{~A})$ & $3.67(\mathrm{~A})$ \\
\hline \hline
\end{tabular}

In Table 3 we present the outcome of tests for restrictions, for the BLE expectations scheme. The results are broadly in agreement with those exhibited in Table 2, for FLE.

Next, we ask ourselves: how do these conclusions compare with the conclusions one might obtain if one specified not a SMARMA model but a SVAR model? The answers are provided in Tables 4 and 5 below for the FLE and BLE expectational schemes respectively.

\section{Table 4}

Tests of Overidentifying Restrictions

Forward Looking Expectations (SVAR)

\begin{tabular}{|r|r|r|r|r|r|}
\hline \hline Eq. & Restriction & & Tests GER & Tests JPN & Tests UK \\
\hline \hline 1 & $\pi_{21}-\pi_{31}+\pi_{41}$ & $=0$ & $3 \mathrm{e}-5(\mathrm{~A})$ & $5 \mathrm{e}-5(\mathrm{~A})$ & $2 \mathrm{e}-5(\mathrm{~A})$ \\
\hline 2 & $\pi_{12}=\pi_{32}=\pi_{52}$ & $=0$ & $7.23^{*}(\mathrm{R})$ & $6.44^{* *}(\mathrm{R})$ & $18.03^{* * *}(\mathrm{R})$ \\
\hline 3 & $\pi_{43}$ & $=0$ & $-0.007^{* * *}(\mathrm{R})$ & $-0.009^{* * *}(\mathrm{R})$ & $4 \mathrm{e}-6(\mathrm{~A})$ \\
\hline 3 & $\pi_{23}+\pi_{53}$ & $=0$ & $8 \mathrm{e}-5(\mathrm{~A})$ & $7 \mathrm{e}-5(\mathrm{~A})$ & $3 \mathrm{e}-6(\mathrm{~A})$ \\
\hline 4 & $\pi_{14}=\pi_{24}$ & $=0$ & $0.003(\mathrm{~A})$ & $0.006(\mathrm{~A})$ & $0.009(\mathrm{~A})$ \\
\hline 4 & $\pi_{34}$ & $=1$ & $-0.174^{* * *}(\mathrm{R})$ & $-0.190(\mathrm{~A})$ & $5 \mathrm{e}-4(\mathrm{~A})$ \\
\hline 5 & $\pi_{15}=\pi_{25}=\pi_{35}=\pi_{45}$ & $=0$ & $(\mathrm{~A})$ & $(\mathrm{A})$ & $(\mathrm{A})$ \\
\hline \hline
\end{tabular}


While the results of Table 4 are by and large in agreement with those of Table 2 (both of which embody FLE) there are some notable differences: with SVAR one invariably rejects the exclusion restrictions of Eq. (2), with SMARMA there is no uniform rejection.

With SMARMA the exclusion of the exchange rate from Eq. (6) is uniformaly accepted; with SVAR this restriction is rejected for Germany and Japan, and is accepted only for the UK.

The no money illusion restriction (in Eq. (3)) is uniformly accepted in SVAR, as well as in SMARMA.

The exclusion restrictions of Eq. (4) are uniformly accepted in both SMARMA and SVAR.

The exogeneity of money (results in last row of the table) is uniformly accepted in both SMARMA and SVAR.

\section{Table 5}

Tests of Overidentifying Restrictions

Backward Looking Expectations (SVAR)

\begin{tabular}{|r|r|r|r|r|r|}
\hline \hline Eq. No & Restriction & & Tests GER & Tests JPN & Tests UK \\
\hline \hline 1 & $\pi_{21}+\pi_{31}-\pi_{41}$ & $=0$ & $1 \mathrm{e}-4(\mathrm{~A})$ & $1 \mathrm{e}-4(\mathrm{~A})$ & $1 \mathrm{e}-4(\mathrm{~A})$ \\
\hline 2 & $\pi_{12}=\pi_{32}=\pi_{52}$ & $=0$ & $31.02^{* * *}(\mathrm{R})$ & $26.96^{* * *}(\mathrm{R})$ & $14.11^{* * *}(\mathrm{R})$ \\
\hline 3 & $\pi_{43}$ & $=0$ & $4 \mathrm{e}-4(\mathrm{~A})$ & $5 \mathrm{e}-4(\mathrm{~A})$ & $-0.08^{* * *}(\mathrm{R})$ \\
\hline 3 & $\pi_{23}+\pi_{53}$ & $=0$ & $2 \mathrm{e}-5(\mathrm{~A})$ & $1 \mathrm{e}-6(\mathrm{~A})$ & $9 \mathrm{e}-5(\mathrm{~A})$ \\
\hline 4 & $\pi_{14}=\pi_{24}$ & $=0$ & $0.097(\mathrm{~A})$ & $0.057(\mathrm{~A})$ & $0.004(\mathrm{~A})$ \\
\hline 4 & $\pi_{34}$ & $=1$ & $0.004(\mathrm{~A})$ & $-0.005(\mathrm{~A})$ & $-0.216^{* * *}(\mathrm{R})$ \\
\hline 5 & $\pi_{15}=\pi_{25}=\pi_{35}=\pi_{45}$ & $=0$ & $3.74(\mathrm{~A})$ & $2.92(\mathrm{~A})$ & $1.19(\mathrm{~A})$ \\
\hline
\end{tabular}

Similarly the results of Table 5 are in broad agreement with those of Table 3 , except that in the case of SVAR some doubts are raised regarding the validity of the exclusion restriction in Eq. (3), and the parity condition of Eq. (4). 
The estimates of the elements of the feedback matrix $\hat{\Pi}_{0}$, are reported in the Appendix in Tables A1 through A4. For the FLE SMARMA, and US vs. Germany, the results of the first equation imply that domestic prices have a negative feedback on real income as does an increase in nominal interest rate; however, an increase in the nominal exchange rate has a positive feedback, other thing being equal. The results are similar for the US vs. Japan and the UK.

From the second equation we note that the results indicate no feedback between the nonminal exchange rate and the price level and this is a result that holds in all three cases.

From the third equation we note that the results indicate that there is no significant feedback between (nominal) interest rate and the price level, but a significant negative feedback between (nominal) interest rate and real income.

We have commented earlier regarding the fourth and fifth equations and need not repeat our remarks now.

For the BLE SMARMA version (Table A2) the same general qualitative conclusions hold, except that the feedbacks are somewhat more pervasive than in the FLE version.

Comparing these results with the SVAR specification in Tables A3 and A4 we note the FLE SVAR version exhibits very weak feedbacks, which is an important finding, given the excessive reliance of the literature on this specification. The BLE SVAR version, however, exhibits similar feedback patterns as the corresponding SMARMA version. Such results if verified with other data sets cast an unfavorable light on the prevaling methods of identification and the consequent derivation of impulse response functions.

A formal test of the FLE versus the BLE versions of rational expectations open economy macro models may be carried out in terms of the significance of current exogenous variables. The results of likelihood ratio tests (LRT) of FLE versus BLE are given in Table A5, and yield an unambigous and strong rejection of BLE in favor of FLE. 
In Tables A6 through $\mathrm{A} 8$ of the Appendix we give the correlation coefficient between predicted (fitted) and actual dependent variables, using the reduced form parameter estimates. The results indicate that both SMARMA and SVAR (using the same number of parameters) are substantially similar in their abilit to "explain" the data. But, in both specifications, some equations like real GDP and price are "better" explained than others like exchange rates, money, and nominal interest.

Finally, in Tables A9 and A10 we present the characteristic roots of the estimate of the covariance matrix in the FLE (first three columns) and BLE (last three columns) for both SMARMA and SVAR. In both instances there is the disturbing phenomenon that the estimates strongly suggest that the matrix in question is of rank 1 , in which case a structural model could not possibly hold. This is so since, if the specification imposed on the data is in fact correct, what we have in the tables are the characteristic roots of a (strongly) consistent estimator of the covariance matrix of the reduced form, which is $\Pi_{0}^{\prime-1} \Pi_{0}^{-1}$. In particular, the last row of the tables indicates that the ratio of the maximal root to the trace (i.e. the sum of all roots) is of the order of $.99+$.

Even though this phenomenon has not been remakrd in the literature, it is a feature that may be disclosed not only by the method of identification given in this paper, but also by the other two methods noted earlier. In our case, the estimate of the covariance matrix in question is an input into the estimation of $\Pi_{0}$ subject to the prior restrictions. In the standard identification procedure favored in the current literature (Blanchard and Quah), this matrix is commingled with $\hat{\Pi}^{*}(1)$ in the detemination of the triangular matrix $S$ and thus does not attract any attention. However, since $\operatorname{rank}(A B) \leq \min [\operatorname{rank}(A), \operatorname{rank}(B)]$ it is as much of a problem to be dealt with there as it is in our case. Needless to say, in the identification method favored earlier (Sims) we are directly engaged in the triangular decomposition of a $q \times q$ matrix, which appears through the empirical estimates to be of rank one rather than $q>1$. 


\section{Conclusions}

In this paper we examine the standard open economy macro model and seek to answer a number of questions. Our formulation contains a a number of novel features:

The major restrictions that are placed on such models in the literature $a b$ initio, and without recourse, are imposed by means of Lagrange multipliers so that tests of the overidentifying restrictions may be carried out routinely.

The model on which estimation is based is formulated as a structural $\operatorname{MARMA}(1,1)$.

We formulate a test of the hypothesis that the expectational scheme is forward looking (FLE) as against the view that it is backward looking (BLE).

We give now the major results as they pertain to the feedback matrix $\Pi_{0}$, which reflects the economics embedded in the model.

Our findings confirm the hypothesis that real income in the home country depends on the real interest rate, and the real exchange rate; this is an equilibrium condition and is incorporated in the first equation of Taylor's formulation (1993).

The exogeneity of money stock is unifromly upheld whether one uses a SMARMA or a SVAR formulation.

The formulation of the price equation as depending only on exchange rates is generally rejected, so that other factors beyond wages and exchange rates affect domestic prices.

Questions are being raised regarding the validity of the (purchasing power) parity condition, but the evidence against it is weak.

In a formal test, the hypothesis that the expectational scheme is backward looking is strongly rejected in favor of a forward looking scheme.

The SMARMA formulation gives results that are somewhat more consistent with economic wisdom such as it may be, and there are perceptible differences depending on whether we employ a SMARMA or 
SVAR formulation.

If we adjust the SVAR model so that it contains the same number of parameters as the SMARMA model, the correlation coefficients between the (reduced form) predicted and actual dependendent variables are roughly similar.

The characteristic roots of the estimated reduced form covariance matrix, which theoretically is of the form $\Pi_{0}^{\prime-1} \Pi_{0}^{-1}$, are uniformly miniscule, except for the largest root; the ratio of the latter to the trace is of the order of .99! This raises serious questions about the integrity of the structural model, particularly so for the commonly applied just identification cases, where the application of prior restrictions obscures this fact. 


\section{REFERENCES}

Blanchard, O. J. and D. Quah (1989), "The Dynamic Effects of Aggregate Demand and Supply Disturbances", American Economic Review, vol. 79, pp. $655-673$.

Clarida, R. and J. Gali (1995), "Sources of Real Exchange Rate Movements: How Important are Nominal Shocks?", Carnegie Rochester Conference Series on Public Policy, vol 35, pp. 81-101.

Campbell, J. and R. Clarida (1987), "The Dollar and Real Interest Rates: An Empirical Investigation", Carnegie Rochester Conference Series on Public Policy, vol. 27, pp. 103-140.

Dhrymes, P. J. (1970), Econometrics: Statistical Foundations and Implications, New York: Harper and Row.

Dhrymes, O. J. (1971), Distributed Lags: Problems of Estimation and Formulation, San Francisco: Holden-Day.

Dhrymes, P. J. (1981), Distributed Lags: Problems of Estimation and Formulation, second edition, Amsterdam: North Holland.

Dhrymes, P. J. (1984), Mathematics for Econometrics, second edition, New York: Springer Verlag.

Dhrymes, P. J. (1994a), "Specification Tests in Simultaneous Equations Systems ", Journal of Econometrics, pp. 45-76.

Dhrymes, P. J. (1994b), Topics in Advanced Econometrics, vol. II, Linear and Nonlinear Simultaneous Equations, New York: Springer Verlag.

Dhrymes, P. J. (1997), "Identification and Estimation of Structural VAR and MARMA Models", Discussion Paper 9697-20, Department of Economics, Columbia University.

Dornbusch, R. (1976), "Expectations and Exchange Rate Dynamics", 
Journal of Political Economy, vol. 84, pp. 1161-1176.

Huizinga, J. (1987), "An Empirical Investigation of the Long Run Behavior of Real Exchange Rates", Carnegie Rochester Conference Series on Public Policy, vol. 27, pp. 149-215.

Lastrapes, W. (1992), "Sources of Flunctuations in Real and Nominal Exchange Rates", Review of Economics and Statistics, vol. pp. 530-539.

Meese, R. and K. Rogoff (1988), "Was it Real?: The Exchange Rate Interest Differential Relation Over the Modern Floating Rate Period", Journal of Finance, vol. 43, pp. 933-948.

Mussa, M. (1986), "Nominal Exchange Rate Regimes and the Behavior of Real Exchange Rates: Evidence and Implications", Carnegie Rochester Conference Series on Public Policy, vol. 25, pp. 117-220.

Obstfeld, M. (1985), "Floating Exchange Rates: Experience and Prospects", Brookings Papers on Economic Activity, vol. 2, pp. 369-450.

Sims, C. A. (1980), "Macroeconomics and Reality", Econometrica, vol. 48, pp. 1-48.

Stockman, A. (1987), "The Equilibrium Approach to Exchange Rates", Federal Reserve Bank of Richmond Economic Review, vol. 73, pp.12-30.

Taylor, J. (1993), Macroeconomic Policy in a World Economy: From Econometric Design to Practical Operation, New York: W. W. Norton and Company. 


\section{APPENDIX}

\section{Table A1}

Coefficient Estimates of Feedback Matrix $\left(\Pi_{0}\right)$

Forward Looking Expectations (SMARMA)

\begin{tabular}{|r|r|r|r|r|r|}
\hline Income & $y_{t 1}$ & $y_{t 2}$ & $y_{t 3}$ & $y_{t 4}$ & $y_{t 5}$ \\
\hline GER & -116.69 & $-11.03^{* * *}$ & $-1.60^{* * *}$ & $9.43^{* * *}$ & -4.25 \\
JPN & 206.27 & $14.65^{* * *}$ & $1.56^{* * *}$ & $-13.09^{* * *}$ & 0.36 \\
UK & 11.04 & $42.62^{* * *}$ & 0.005 & $-42.61^{* * *}$ & -2.60 \\
\hline \hline Price & $y_{t 1}$ & $y_{t 2}$ & $y_{t 3}$ & $y_{t 4}$ & $y_{t 5}$ \\
\hline GER & n.a. & $-1007.13^{* * *}$ & n.a. & -1.35 & n.a. \\
JPN & n.a. & $1052.23^{* * *}$ & n.a. & 3.07 & n.a. \\
UK & n.a. & 981.49 & n.a. & 5.05 & n.a. \\
\hline \hline Int. Rate & $y_{t 1}$ & $y_{t 2}$ & $y_{t 3}$ & $y_{t 4}$ & $y_{t 5}$ \\
\hline GER & $626.06^{* * *}$ & 15.17 & -0.14 & n.a. & -15.17 \\
JPN & $-616.62^{* * *}$ & -7.96 & 0.41 & n.a. & 7.96 \\
UK & -562.11 & -7.78 & -0.19 & n.a. & 7.78 \\
\hline \hline Exch. Rate & $y_{t 1}$ & $y_{t 2}$ & $y_{t 3}$ & $y_{t 4}$ & $y_{t 5}$ \\
\hline GER & n.a. & n.a. & 1 & $35.64^{* * *}$ & 1.61 \\
JPN & n.a. & n.a. & 1 & -0.01 & 1.43 \\
UK & n.a. & n.a. & 1 & $4.84^{* * *}$ & 3.97 \\
\hline \hline Money & $y_{t 1}$ & $y_{t 2}$ & $y_{t 3}$ & $y_{t 4}$ & $y_{t 5}$ \\
\hline GER & n.a. & n.a. & n.a. & n.a. & $78.36^{* * *}$ \\
JPN & n.a. & n.a. & n.a. & n.a. & $72.34^{* * *}$ \\
UK & n.a. & n.a. & n.a. & n.a. & $75.43^{* * *}$ \\
\hline \hline
\end{tabular}

In the preceding, and all other tables, we employ the convention that a *, ${ }^{* *},{ }^{* * *}$ indicates significance at the $10 \%, 5 \%$ and $1 \%$ level, respectively. 
Table A2

Coefficient Estimates of Feedback Matrix $\left(\Pi_{0}\right)$

Backward Looking Expectations (SMARMA)

\begin{tabular}{|r|r|r|r|r|r|}
\hline \hline Income & $y_{t 1}$ & $y_{t 2}$ & $y_{t 3}$ & $y_{t 4}$ & $y_{t 5}$ \\
\hline GER & 201.24 & $12.08^{* *}$ & $1.54^{* * *}$ & $-10.54^{*}$ & n.a. \\
JPN & 213.12 & $14.59^{* * *}$ & $1.54^{* * *}$ & $-13.05^{* * *}$ & n.a. \\
UK & 24.03 & $16.90^{* * *}$ & $1.46^{* * *}$ & $-15.44^{* * *}$ & n.a. \\
\hline \hline Price & $y_{t 1}$ & $y_{t 2}$ & $y_{t 3}$ & $y_{t 4}$ & $y_{t 5}$ \\
\hline GER & n.a. & $846.17^{* * *}$ & n.a. & -3.30 & n.a. \\
JPN & n.a. & $801.43^{* * *}$ & n.a. & -0.24 & n.a. \\
UK & n.a. & $698.37^{* * *}$ & n.a. & 1.68 & n.a. \\
\hline \hline Int. Rate & $y_{t 1}$ & $y_{t 2}$ & $y_{t 3}$ & $y_{t 4}$ & $y_{t 5}$ \\
\hline GER & $-604.11^{*}$ & $-18.62^{* *}$ & 0.44 & n.a. & $18.62^{* *}$ \\
JPN & $-590.24^{*}$ & $-14.18^{*}$ & 0.43 & n.a. & $14.18^{*}$ \\
UK & $-542.27^{* * *}$ & -5.36 & -0.17 & n.a. & 5.36 \\
\hline \hline Exch. Rate & $y_{t 1}$ & $y_{t 2}$ & $y_{t 3}$ & $y_{t 4}$ & $y_{t 5}$ \\
\hline GER & n.a. & n.a. & 1 & $38.21^{* * *}$ & n.a. \\
JPN & n.a. & n.a. & 1 & $35.35^{* * *}$ & n.a. \\
UK & n.a. & n.a. & 1 & $40.57^{* * *}$ & n.a. \\
\hline Money & $y_{t 1}$ & $y_{t 2}$ & $y_{t 3}$ & $y_{t 4}$ & $y_{t 5}$ \\
\hline GER & n.a. & n.a. & n.a. & n.a. & $68.21^{* * *}$ \\
JPN & n.a. & n.a. & n.a. & n.a. & $68.42^{* * *}$ \\
UK & n.a. & n.a. & n.a. & n.a. & $61.91^{* * *}$ \\
\hline \hline
\end{tabular}




\section{Table A3}

Coefficient Estimates of Feedback Matrix $\left(\Pi_{0}\right)$ Forward Looking Expectations (SVAR)

\begin{tabular}{|r|r|r|r|r|r|}
\hline \hline Income & $y_{t 1}$ & $y_{t 2}$ & $y_{t 3}$ & $y_{t 4}$ & $y_{t 5}$ \\
\hline GER & $606.61^{* *}$ & -0.19 & $7 \mathrm{e}-4$ & 0.19 & -13.28 \\
JPN & 595.02 & -0.53 & -0.38 & 0.14 & 12.76 \\
UK & 5.80 & $-19.14^{* * *}$ & $-1.45^{* * *}$ & $17.68^{* * *}$ & -6.38 \\
\hline \hline Price & $y_{t 1}$ & $y_{t 2}$ & $y_{t 3}$ & $y_{t 4}$ & $y_{t 5}$ \\
\hline GER & n.a. & $958.23^{* * *}$ & n.a. & -1.98 & n.a. \\
JPN & n.a. & $976.32^{* * *}$ & n.a. & 0.34 & n.a. \\
UK & n.a. & $956.81^{* * *}$ & n.a. & $5.08^{* *}$ & n.a. \\
\hline Int. Rate & $y_{t 1}$ & $y_{t 2}$ & $y_{t 3}$ & $y_{t 4}$ & $y_{t 5}$ \\
\hline GER & 54.82 & -9.28 & $1.73^{* * *}$ & n.a. & 9.28 \\
JPN & 165.45 & -8.00 & 1.77 & n.a. & 8.00 \\
UK & $541.96^{* * *}$ & 6.38 & 0.18 & n.a. & -6.38 \\
\hline \hline Exch. Rate & $y_{t 1}$ & $y_{t 2}$ & $y_{t 3}$ & $y_{t 4}$ & $y_{t 5}$ \\
\hline GER & n.a. & n.a. & 1 & $39.66^{* * *}$ & 3.96 \\
JPN & n.a. & n.a. & 1 & $37.36^{* * *}$ & 2.28 \\
UK & n.a. & n.a. & 1 & $39.70^{* * *}$ & 3.43 \\
\hline \hline Money & $y_{t 1}$ & $y_{t 2}$ & $y_{t 3}$ & $y_{t 4}$ & $y_{t 5}$ \\
\hline GER & n.a. & n.a. & n.a. & n.a. & $75.43^{* * *}$ \\
JPN & n.a. & n.a. & n.a. & n.a. & $74.04^{* * *}$ \\
UK & n.a. & n.a. & n.a. & n.a. & $74.74^{* * *}$ \\
\hline \hline
\end{tabular}


Table A4

Coefficient Estimates of Feedback Matrix $\left(\Pi_{0}\right)$ Backward Looking Expectations (SVAR)

\begin{tabular}{|r|r|r|r|r|r|}
\hline \hline Income & $y_{t 1}$ & $y_{t 2}$ & $y_{t 3}$ & $y_{t 4}$ & $y_{t 5}$ \\
\hline GER & 88.06 & $14.17^{* * *}$ & $1.46^{* * *}$ & -12.70 & n.a. \\
JPN & 139.23 & $15.87^{* * *}$ & $1.44^{* * *}$ & $-14.43^{* * *}$ & n.a. \\
UK & $534.33^{* * *}$ & -0.68 & 0.06 & 0.73 & n.a. \\
\hline \hline Price & $y_{t 1}$ & $y_{t 2}$ & $y_{t 3}$ & $y_{t 4}$ & $y_{t 5}$ \\
\hline GER & n.a. & $777.05^{* * *}$ & n.a. & -0.92 & n.a. \\
JPN & n.a. & $774.34^{* * *}$ & n.a. & 0.64 & n.a. \\
UK & n.a. & $708.89^{* * *}$ & n.a. & 1.27 & n.a. \\
\hline \hline Int. Rate & $y_{t 1}$ & $y_{t 2}$ & $y_{t 3}$ & $y_{t 4}$ & $y_{t 5}$ \\
\hline GER & $-601.90^{* * *}$ & $-14.86^{* *}$ & 0.08 & n.a. & $14.86^{* *}$ \\
JPN & $-594.50^{* * *}$ & $-14.66^{* *}$ & 0.21 & n.a. & $14.66^{* *}$ \\
UK & -36.36 & -3.53 & $1.72^{* * *}$ & n.a. & 3.53 \\
\hline \hline Exch. Rate & $y_{t 1}$ & $y_{t 2}$ & $y_{t 3}$ & $y_{t 4}$ & $y_{t 5}$ \\
\hline GER & n.a. & n.a. & 1 & $36.11^{* * *}$ & n.a. \\
JPN & n.a. & n.a. & 1 & $33.43^{* * *}$ & n.a. \\
UK & n.a. & n.a. & 1 & $44.12^{* * *}$ & n.a. \\
\hline \hline Money & $y_{t 1}$ & $y_{t 2}$ & $y_{t 3}$ & $y_{t 4}$ & $y_{t 5}$ \\
\hline GER & n.a. & n.a. & n.a. & n.a. & $68.80^{* * *}$ \\
JPN & n.a. & n.a. & n.a. & n.a. & $68.92^{* * *}$ \\
UK & n.a. & n.a. & n.a. & n.a. & $69.72^{* * *}$ \\
\hline \hline
\end{tabular}




\section{Table A5}

\section{Likelihood Ratio Tests for the}

Significance of Current Exogenous Variables

FLE versus BLE

\begin{tabular}{|r|r|r|}
\hline \hline Case & LRT $_{\text {MARMA }}$ & LRT $_{V A R}$ \\
\hline \hline US vs. GER & $72.417^{* * *}$ & $54.952^{* * *}$ \\
\hline US vs. JPN & $110.820^{* * *}$ & $72.698^{* * *}$ \\
\hline US vs. UK & $261.187^{* * *}$ & $135.245^{* * *}$ \\
\hline \hline
\end{tabular}

\section{Table A6}

Correlations between Actual and Fitted Values, US vs. GER

\begin{tabular}{|c|r|r|r|r|}
\hline \hline Eq. & SMARMA-F & SMARMA-B & SVAR-F & SVAR-B \\
\hline \hline$y_{t 1}$ & 0.804 & 0.799 & 0.807 & 0.800 \\
\hline$y_{t 2}$ & 0.889 & 0.838 & 0.883 & 0.811 \\
\hline$y_{t 3}$ & 0.594 & 0.601 & 0.603 & 0.602 \\
\hline$y_{t 4}$ & 0.305 & 0.361 & 0.406 & 0.398 \\
\hline$y_{t 5}$ & 0.590 & 0.376 & 0.588 & 0.447 \\
\hline \hline
\end{tabular}

Table A7

Correlations between Actual and Fitted Values, US vs. JPN

\begin{tabular}{|c|r|r|r|r|}
\hline \hline Eq. & SMARMA-F & SMARMA-B & SVAR-F & SVAR-B \\
\hline \hline$y_{t \mathbf{1}}$ & 0.816 & 0.795 & 0.816 & 0.800 \\
\hline$y_{t 2}$ & 0.898 & 0.818 & 0.888 & 0.811 \\
\hline$y_{t 3}$ & 0.634 & 0.619 & 0.652 & 0.602 \\
\hline$y_{t 4}$ & 0.410 & 0.392 & 0.408 & 0.398 \\
\hline$y_{t 5}$ & 0.495 & 0.382 & 0.566 & 0.447 \\
\hline \hline
\end{tabular}


Table A8

Correlations between Actual and Fitted Values US vs. UK

\begin{tabular}{|r|r|r|r|r|}
\hline \hline Eq. & SMARMA-F & SMARMA-B & SVAR-F & SVAR-B \\
\hline \hline$y_{t 1}$ & 0.800 & 0.784 & 0.802 & 0.795 \\
\hline$y_{t 2}$ & 0.911 & 0.816 & 0.912 & 0.832 \\
\hline$y_{t 3}$ & 0.486 & 0.429 & 0.502 & 0.477 \\
\hline$y_{t 4}$ & 0.471 & 0.448 & 0.523 & 0.470 \\
\hline$y_{t 5}$ & 0.563 & 0.176 & 0.593 & 0.493 \\
\hline \hline
\end{tabular}

Table A9

Characteristic Roots of Estimate of the Reduced Form

Covariance Matrix, and Ratio of Maximal Root

to Trace $(M / T)$, SMARMA

\begin{tabular}{|r|r|r|r|r|r|r|}
\hline \hline Root & GER & JPN & UK & GER & JPN & UK \\
\hline \hline 1 & $1 \mathrm{e}-6$ & $1 \mathrm{e}-6$ & $1 \mathrm{e}-6$ & $1 \mathrm{e}-6$ & $1 \mathrm{e}-6$ & $2 \mathrm{e}-6$ \\
\hline 2 & $2 \mathrm{e}-6$ & $2 \mathrm{e}-6$ & $3 \mathrm{e}-6$ & $2 \mathrm{e}-6$ & $3 \mathrm{e}-6$ & $3 \mathrm{e}-6$ \\
\hline 3 & $1 \mathrm{e}-4$ & $2 \mathrm{e}-4$ & $2 \mathrm{e}-4$ & $2 \mathrm{e}-4$ & $2 \mathrm{e}-4$ & $2 \mathrm{e}-4$ \\
\hline 4 & $6 \mathrm{e}-4$ & $7 \mathrm{e}-4$ & $5 \mathrm{e}-4$ & $6 \mathrm{e}-4$ & $7 \mathrm{e}-4$ & $5 \mathrm{e}-4$ \\
\hline 5 & 0.315 & 0.291 & 0.320 & 0.311 & 0.300 & 0.341 \\
\hline \hline $\mathrm{M} / \mathrm{T}$ & 0.997 & 0.997 & 0.997 & 0.997 & 0.997 & 0.997 \\
\hline \hline
\end{tabular}

Table A10

Characteristic Roots of Estimate of the Reduced Form

Covariance Matrix, and Ratio of Maximal Root

to Trace $(\mathrm{M} / \mathrm{T})$, SVAR 


\begin{tabular}{|r|r|r|r|r|r|r|}
\hline \hline Root & GER & JPN & UK & GER & JPN & UK \\
\hline \hline 1 & $1 \mathrm{e}-6$ & $1 \mathrm{e}-6$ & $1 \mathrm{e}-6$ & $1 \mathrm{e}-6$ & $1 \mathrm{e}-6$ & $2 \mathrm{e}-6$ \\
\hline 2 & $3 \mathrm{e}-6$ & $3 \mathrm{e}-6$ & $3 \mathrm{e}-6$ & $3 \mathrm{e}-6$ & $3 \mathrm{e}-6$ & $3 \mathrm{e}-6$ \\
\hline 3 & $2 \mathrm{e}-4$ & $2 \mathrm{e}-4$ & $2 \mathrm{e}-4$ & $2 \mathrm{e}-4$ & $2 \mathrm{e}-4$ & $2 \mathrm{e}-4$ \\
\hline 4 & $7 \mathrm{e}-4$ & $7 \mathrm{e}-4$ & $5 \mathrm{e}-4$ & $7 \mathrm{e}-4$ & $7 \mathrm{e}-4$ & $5 \mathrm{e}-4$ \\
\hline 5 & 0.342 & 0.309 & 0.335 & 0.343 & 0.336 & 0.341 \\
\hline \hline $\mathrm{M} / \mathrm{T}$ & 0.997 & 0.997 & 0.998 & 0.997 & 0.997 & 0.998 \\
\hline \hline
\end{tabular}




\title{
1997-1998 Discussion Paper Series
}

\author{
Department of Economics \\ Columbia University \\ 1022 International Affairs Bldg. \\ 420 West 118 th Street \\ New York, N.Y., 10027
}

The following papers are published in the 1997-98 Columbia University Discussion Paper series which runs from early November to October 31 of the following year (Academic Year).

The following is a website address where viewers may download some discussion papers. It is a project that is in progress, and therefore the site may not contain all recent working papers.

http://www.columbia.edu/dlc/wp/econ/index.html.

For Ordering Hardcopies:

Domestic orders for discussion papers are available for purchase at the cost of $\$ 8.00$ (U.S.) Per paper and $\$ 140.00$ (US) for the series.

Foreign orders cost $\$ 10.00$ (US) per paper and $\$ 185.00$ for the series.

To order discussion papers, please write to the Discussion Paper Coordinator at the above address along with a check for the appropriate amount, made payable to Department of Economics, Columbia University. Please be sure to include the series number of the requested paper when you place an order. 
1997-98 Discussion Papers

Economics Department, Columbia University

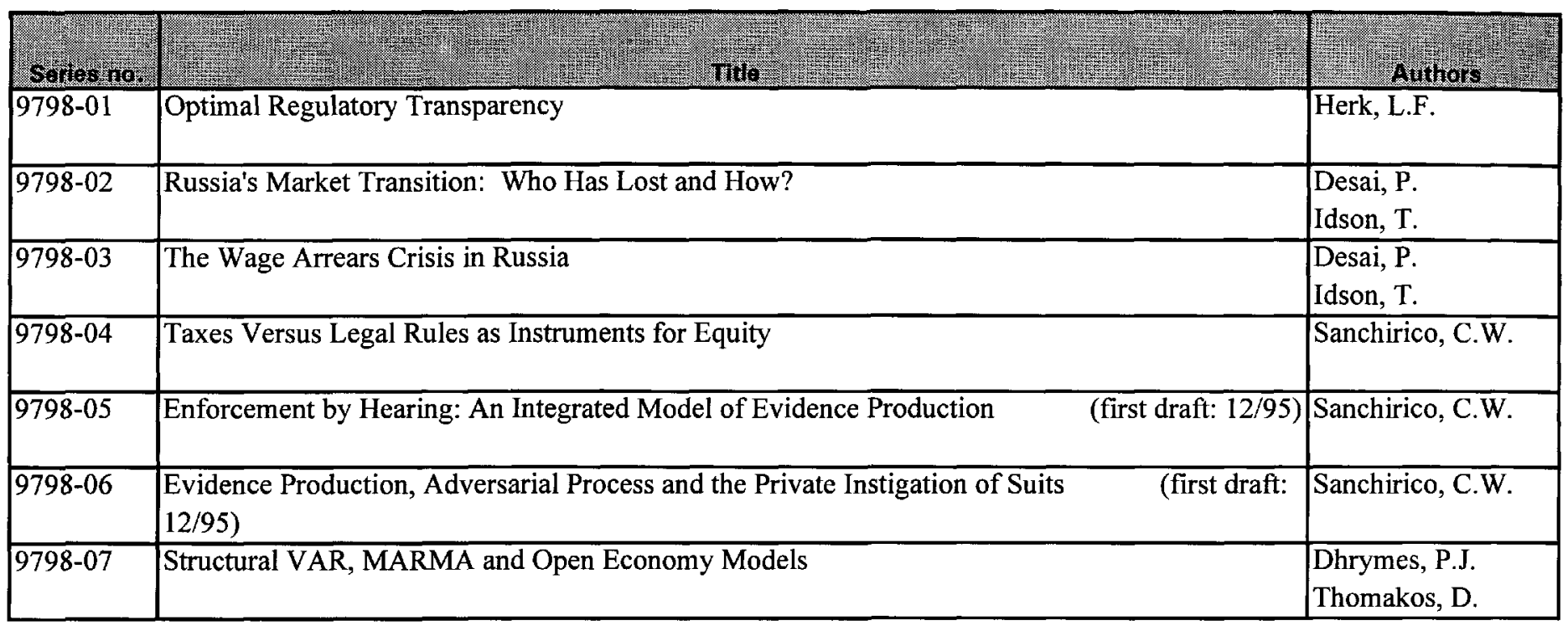

